\title{
The future of biological therapy: a pathway forward for biosimilars
}

Richard O Dolinar, MD; Michael S Reilly

Biologicals are advanced prescription drugs to treat cancer, rheumatoid arthritis HIV/AIDS, multiple sclerosis and other debilitating diseases. In November 2010, the US Food and Drug Administration (FDA) began consultation with patient groups, physicians and industry on how to approve the first copies of these drugs, known as follow-on biologics in the US or biosimilars. As FDA moves forward in implementing this pathway, it is essential that all stakeholders work together to ensure patient safety remains the top priority to achieve safe and efficacious patient care.

Keywords: Biologicals, biosimilars, FDA guidelines, patient safety, pharmacovigilance

\section{Introduction}

Biologicals are large, complex molecule drugs that treat serious illnesses. They are created using proprietary and unique processes involving living cells, and range from sugars and proteins to tissues and nucleic acids [1]. Examples of biologicals can be found in vaccines, certain blood treatments, and gene therapy [2]. Biological medicines are unique because, unlike more established drugs, they are not chemically synthesized. According to the US Food and Drug Administration (FDA), biologicals 'often represent the cuttingedge of biomedical research and, in time, may offer the most effective means to treat a variety of medical illnesses and conditions that presently have no other treatments available' [2]. In fact, it is estimated that by 2016, biological medicines will comprise 48 per cent of the top 100 best-selling drugs [3].

Continued improvements in manufacturing efficiency, increasing access to these drugs and reducing costs are as important as new discoveries. Most importantly, with FDA outlining its latest guidance at the end of 2012 for the future of biological medicines, patient safety must be the primary focus of all stakeholders.

\section{Biologicals meet biosimilars}

Although the breakthroughs in biologicals have been groundbreaking, the future of health care is not just about new molecules. It is also about the new and exciting frontier of biosimilars, also known as 'followon biologics' in the US; biosimilars are products that enter the marketplace after the patent of an 'innovator drug' expires, in this case a certain biological.

Biosimilars have similar properties to existing biological products (hence the term 'biosimilar'), therefore, patients can rest assure of the efficacy of these biological therapies. As the Generics and Biosimilars Initiative (GaBI) points out, FDA states that there are "no clinically meaningful differences between the biological product and the reference product in terms of the safety, purity, and potency of the product' [4].

Importantly, however, due to the complexity of biologicals, a 'follow-on biologic' can only be made similar, rather than identical. Most of the discussion between biologicals and biosimilars contained herein this paper, moreover, is about switching, rather than the initial selection of these medicines.
It is always important to frame a discussion of biosimilars by remembering that there is no such thing as a generic biological. 'Big' molecules (biologicals) are more than just a larger version of 'small' chemically synthesized ones. Biologicals are created from living organisms and are not as simple to replicate as traditional drugs, such as aspirin and antihistamines. A biosimilar is not a generic drug, and that is more than just a detail.

Because of the complexity of manufacturing a biosimilar, it is imperative that FDA implements a system - a pathway which provides complete transparency to patients and their physicians. An example of this patient-centered pathway is encouraging US States to require pharmacists to secure a patient's consent prior to substituting an interchangeable biological product for the one prescribed, or at a minimum to ensure that treating physicians are notified when a substitution has occurred. Undoubtedly, it is in the patient's best interest to have the pharmacist and physician work together.

The prescribing physician should be notified of the switch in a timely manner. Additionally, a strong track and trace system is needed to detect side effects, both to determine the rate at which rare events occur and to identify those not known at the time of market entry. Keeping patients and physicians in the healthcare decisionmaking process ameliorates potential harm to the patient in the event a product is found to have adverse side effects after it enters the market.

\section{Today's biologicals defined}

Novel biologicals act by novel targets, technology platforms and/or mechanisms of action compared with previously approved biologicals.

Next-generation biologicals ('biobetters') have the same target or mechanism of action as a previously approved biological but include structural changes, bi-functional targeting (with or without a biosimilar core) or an improved formulation that may result in an expected improvement in clinical profile.

Because biological therapeutics are highly complex and large protein molecules, 
they require a wide variety of analytical methods to ensure consistent quality. Indeed, given the complexity of biologicals and their manufacture (in which living cells produce the core molecule and make post-translational modifications), the innovator product has inherent lotto-lot variability. In light of this inherent variability and the diverse and complex analytical methodologies required to characterize the molecules, it is not realistic to exactly replicate an innovator molecule. Therefore, the concept of a biosimilar is to make a molecule that is as similar to the innovator as possible. Accordingly, follow-on molecules in the biological space are termed biosimilars, rather than biogenerics.

Biosimilars are structurally highly similar versions of marketed biological medicines. They will have been evaluated and approved by a regulatory authority on the basis of analytical and clinical comparison to the already marketed product.

Across the globe, with the goal of making biologicals more accessible, regulators either have adopted or are considering legislation or regulations to establish pathways for the approval of biosimilars. Because biosimilars are never exact copies of the innovator medicine, establishing appropriate standards for biosimilarity remains an important area for scientific, legislative and regulatory debate [5].

It is important for legislators and regulators to promote safety and science when crafting new policy pertaining to these life-saving medicines. That is why the Alliance for Safe Biologic Medicines (ASBM) works to promote four key principles as US regulators implement an approval pathway for biosimilars:

- prioritizing patient safety

- leveraging what we know

- promoting pharmacovigilance

- keeping physicians engaged.

\section{Prioritizing patient safety}

Biotechnology companies that seek FDA approval for an interchangeable biosimilar need to demonstrate, through de novo clinical trials, that switches from the biosimilar to the reference innovator product (and vice versa) have no negative effect on safety and/or effectiveness, particularly as a result of immunogenicity. It is also important to realize that for one product, the risk of immunogenicity may differ depending on the therapeutic indication [6].

In fact, when it comes to biosimilars, the most important issues facing global drug regulators are the scientific and technical factors related to a determination of biosimilarity. Minor differences in manufacturing processes, such as different host cells, cell culture and purification methods, can have a clinically significant impact on a biological's safety and effectiveness. It is not just whether or not a biosimilar 'works', it is about whether or not it works as well or in the same way once it is administered to a patient. Just as no two patients are exactly alike, neither are biosimilars identical to the innovator product.

The age of 'personalized medicine' is predicated on the 'four rights'-being able to administer the right medicine to the right patient in the right dose at the right time [7].

One issue at the forefront of the biosimilars debate is that of 'switching'-changing a patient's therapy from the innovator product to a biosimilar. Since biosimilars are not identical to their innovator products, many nations around the world have clearly stated that automatic substitution is inappropriate. Because biosimilars generally cost less than innovator drugs, there is significant economic pressure to switch patients to lower cost biosimilars. But when cost-centric concerns are allowed to trump the practice of patient-centric medicine, there is a potential negative impact on both patient safety and clinical effectiveness. The decision to switch a patient must be a clinical one made by the treating physician rather than a legislator, regulator, or insurance provider.

The United States is the only nation that requires its regulatory authority to evaluate whether a biosimilar is similar enough to the already marketed 'reference' product that it can be substituted without physician intervention, permission or authorization. Under US law, FDA would designate such products 'interchangeable'. In addition to scientific challenges associated with making such a designation, there are substantial administrative hurdles that, if not effectively addressed, could jeopardize patient safety.

\section{Leveraging what we know}

Regardless of whether you live in the EU, US or Canada, people might see the prescription drug approval process as mysterious and arcane and have never heard of biosimilars, follow-on biologics or subsequent entry biologics (SEBs). In the US, the regulatory pathway for approval of biosimilars is still in its very early stages, lagging behind the regulatory bodies in the EU and Canada. There are many contentious issues surrounding the 'biosimilar pathway'. Some are economic and focus on legal concerns such as patents and data exclusivity, but these are not within the purview of FDA. What rightly concerns the US drug regulator is safety and efficacy.

The Patient Protection and Affordable Care Act empowered FDA to develop a biosimilar pathway. Having the authority is one thing, getting it done in a timely, suitable, and scientifically robust manner is something else altogether. While FDA retains many of the best regulatory scientists in the world, its human and capital resources are severely limited. Rather than creating a biosimilar pathway from scratch, the US needs not reinvent the wheel. The European Medicines Agency (EMA) began to establish the first formal regulatory pathway for biosimilars in 2003, and that process can serve as a baseline model upon which the US can build.

In February 2012, FDA issued three highly anticipated documents providing guidance on its biosimilar approval pathway. This guidance set forth FDA's current thoughts on 'key scientific and regulatory factors involved in submitting an application for biosimilar products' [8]. The documents help clarify application processes mandated under the new abbreviated regulatory pathway that was included in the Patient Protection and Affordable Care Act.

According to the agency, 'Healthcare professionals and consumers can be assured that the FDA will require licensed biosimilar and interchangeable biological products to meet the Agency's exacting standards of safety and efficacy' [9].

Any biosimilar approval should be based upon the overall assessment of biosimilarity to the innovator through robust analytical, non-clinical and clinical data. For some biological molecules, certain studies may not be necessary. In the event that a biosimilar manufacturer is seeking approval for multiple indications, 


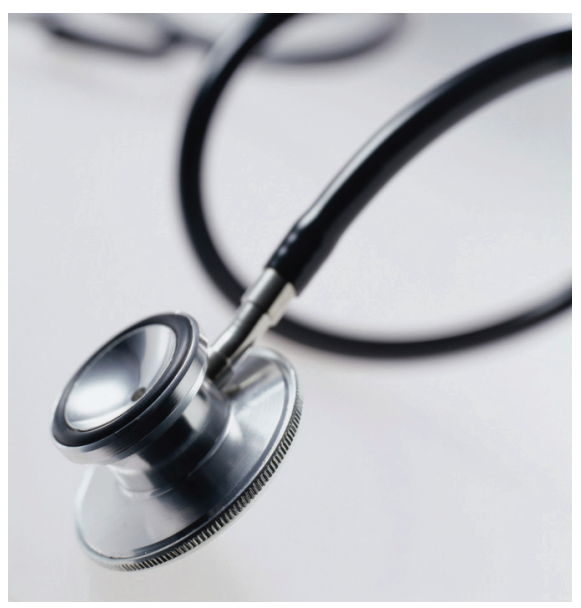

extrapolation of data should be scientifically justified.

By pioneering in this regulatory area for the last eight years, the EU has gathered much data, which can, at a minimum, help inform policymakers. US policymakers should take advantage of this opportunity to learn from the experiences of their counterparts, both the positive and negative.

\section{Promoting pharmacovigilance}

Pharmacovigilance is the surveillance of a drug's performance, particularly of adverse reactions, after it has been released for marketing. As biosimilars may be approved based on less data, pharmacovigilance plays an even more important role. Before biosimilars are thoroughly introduced into the US marketplace, a robust traceability system - including distinctive labels, distinguishable names, product tracking codes, and a way to report adverse events - must be in place to facilitate accurate surveillance.

Through enhanced, 21st century pharmacovigilance, the US can do a better job analyzing data and drawing conclusions relative to many unknown differences between innovator products and biosimilars. The forces of globalization have enabled many other nations to work together to promote pharmacovigilance. As of 2010, 134 nations are party to the World Health Organization (WHO) pharmacovigilance programme [10]. This WHO pharmacovigilance initiative 'aims ... to enhance patient care and patient safety in relation to the use of medicines; and to support public health programmes by providing reliable, balanced information for the effective assessment of the riskbenefit profile of medicines' [10]. It is only by embracing this type of understanding of how biosimilars impact patient health in this 'real world' that patients will be able to use them in the most appropriate way to achieve the best outcomes for their personalized needs. As former Eli Lilly \& Co CEO, Mr Sidney Taurel stated at the Cleveland Clinic, 'The time is ripe for FDA, the healthcare industry, and the medical community to collaborate on a reform of our nation's pharmacovigilance system. Such reform will allow us to speed up the recognition of safety signals and understand the true efficacy of new medicines more quickly' [11].

Automatic substitution complicates the pharmacovigilance that is needed for all biological and biosimilar medicines to ensure safety for patients. Pharmacovigilance is facilitated when physicians make the decision to substitute a biosimilar product. Automatic substitution makes biosimilar pharmacovigilance significantly more difficult. There should be greater clarity and transparency in state substitution laws, and attention must be paid to any prospective policies that infringe physicians' freedom to prescribe the medicines that they deem most appropriate for a particular patient. The need to improve and expand pharmacovigilance systems must also be applied to any changes made in originator biologicals since they may also cause unintended outcomes. To quote Dr Woodcock, 'Our improving the use of marketed drugs, to a great extent, is going to involve partnering with the growing patient safety movement. The vast majority of harm from approved drugs comes from misuse, inappropriate use ... failure to use, abuse and medical mix-ups' [8].

When it comes to biosimilars-primum non nocere (first do no harm).

Complex and extreme challenges often require creative solutions. An excellent example of this is the development of biobetters. Biobetters are to biosimilars what Apple's iPod Touch is to its iPod Shuffle. Where a biosimilar will be a mere structural imitation, a biobetter will possess some molecular or chemical modification that constitutes an improvement over the originator drug. As such, it must be evaluated and approved through the traditional pathway.

Such enhancements may range from a longer half-life, allowing for less frequent dosing, to more potency or less toxicity. That is innovation driven by the new reality of biosimilar competition. And it should not be surprising since, among other things, competition drives innovation.

\section{Keeping physicians engaged}

Sir William Osler, widely regarded as the father of modern medicine, wrote 'If you listen carefully to the patient they will tell you the diagnosis.' Arriving at a diagnosis and appropriate treatment plan has always represented intimate collaboration between patients and physicians.

But today, physicians are increasingly seeing the decisions that they and their patients reach about specific treatment plans second guessed by distant 'third parties', working for government agencies or insurance providers, who may not be aware of the unique individual circumstances of a particular patient.

Physicians must practice both the art and science of medicine, but the issue of cost threatens to interpose itself between physicians and patients. While cost is certainly a crucial topic when it comes to health care, it cannot trump patient safety.

And nowhere is this debate more immediate, urgent, or profound than when it comes to the issue of therapeutic switching, that is, switching patients between products not considered interchangeable. Physicians carefully collaborate with their patients to choose the most appropriate treatment, considering the patient's disease state, ability to tolerate side effects, and stage of life. The crucial differences between biosimilars and small molecule generics are that biosimilars are difficult and expensive to get approved, complicated and challenging to manufacture, and generally have a short shelf life. The savings are expected to track the experience in Europe to date and reflect a 10-30\% discount from the originator product rather than $90 \%$, as with chemical drugs.

Reformers need to recognize that policies giving healthcare administrators control over treatment regimes are hazardous to patient health, and actually inflate overall costs.

In Europe, regulatory authorities understand that the successful adoption of biosimilars requires physician buy-in and for that reason EMA advises that the physician 
should be in charge of the decision to switch between the reference product and biosimilar, or vice versa [12]. Physician confidence translates into increased utilization and in fact, biosimilar medicines have gained a foothold in some European countries as a result of a strategy to persuade physicians to start new patients on a biosimilar rather than switch existing patients [13].

There is a need of enhancing the 'biological experience' for physicians/prescribers. Adequate physician education, sufficient clinical data and appropriate reimbursement services for physicians will result in greater use of biologicals and biosimilars [14].

The repercussions of choosing short-term savings over long-term results, of costbased choices over patient-centric care, of 'fail first' policies over the right treatment for the right patient at the right time-are pernicious to both the public purse and the public health.

\section{Conclusion}

The explosive growth of biological medicines, and the emergence of biosimilars as revolutionary tools to fight the most difficult of diseases, is cause for great celebration in the fight to provide advanced health care to patients worldwide. By abiding by the general principles of prioritizing patient safety, leveraging the information we know, promoting pharmacovigilance and keeping physicians engaged, a golden age for innovative and affordable health care is within reach.

As indicated in an FDA hearing on its biosimilar guidelines in Washington DC, USA, in May 2012, the debate over the future of the biosimilar approval pathway is far from over [15]. Issues in need of further consideration include, among others, defining proteins, stricter methodology in labelling and naming biosimilars.

It is important to note that, although beyond the scope of this paper - which focused on switching between biological products - biosimilars can sometimes be used as the initial and only therapy. Also, the manufacture of innovator products can involve changes that require tracking of outcomes.

In fact, biosimilar medicines have gained a foothold in some European countries as a result of a strategy to persuade physicians to start new patients on a biosimilar rather than switch existing patients [14].

The future of biological medicines will be bright if patients, physicians, biotechnology companies, and other stakeholders work together to ensure patient safety is the foremost priority of the biosimilar policy discussion. Then, the future of healthcare debate can move beyond partisan discussion over healthcare access and cost, to a discussion of the diseases that biological medicines can successfully conquer next.

\section{For patients}

Biologicals and biosimilars are not covered under the 1984 Hatch-Waxman Act, which created an abbreviated approval process for generic versions of conventional drugs. On 23 March 2010, however, the Patient Protection and Affordable Care Act was signed in to law and included a pathway for the approval of biosimilars (also referred to as the Biologics Price Competition and Innovation Act). This abbreviated approval pathway for biosimilars gives FDA the authority to define the implementation process. The law also gives FDA the authority to further define the detail regarding scientific standards and the extent of analytical, preclinical and clinical data necessary for the approval biosimilars to ensure patient safety and the effectiveness of the biosimilar.

As FDA moves forward with the process it is important for patients, physicians, pharmacists, and all other stakeholders to be engaged in these efforts to ensure that the top priority for US regulators is patient safety. Our hope is that the principles outlined in this paper will help them to achieve this worthy goal for patients.

\section{Acknowledgement}

Dr Brett Johnson with the International Cancer Advocacy Network (ICAN) also contributed to the production of this paper.

\section{Funding sources}

The Alliance for Safe Biologic Medicines (ASBM) is an organization composed of diverse healthcare groups and individuals-from patients to physicians, innovative medical biotechnology companies and others who are working together to ensure patient safety is at the forefront of the bio- similars policy discussion. The activities of ASBM are funded by its member partners, who contribute to ASBM's activities, with the primary funding provided by the Steering Committee, funds the ASBM's efforts. ASBM's Steering Committee is comprised of Alliance for Patient Access, American Academy of Dermatology, American Association of People with Disabilities, Association of Clinical Research Organizations, Colon Cancer Alliance, Genentech, Global Healthy Living Foundation, Health HIV and Kidney Cancer Association. It is the mission of the ASBM to serve as an authoritative resource center of information for the public, medical community, FDA and other government staff during the implementation of the biosimilars approval pathway and beyond.

Disclosure of financial and competing interests: Dr Richard O Dolinar, Chairman of the Alliance for Safe Biologic Medicines (ASBM) and Michael S Reilly, Executive Director of the Alliance for Safe Biologic Medicines; are the primary authors of the paper. Both authors are employed by ASBM.

This paper was funded by the Alliance for Safe Biologic Medicines and represents the policies of the organization.

Provenance and peer review: Not commissioned; externally peer reviewed.

\section{Authors}

Dr Richard O Dolinar, Chairman

Michael S Reilly, Executive Director

Alliance for Safe Biologic Medicines, PO

Box 3691 Arlington, VA 22203, USA

\section{References}

1. U.S. Department of Health and Human Services (HHS) [homepage on the Internet]. What is a biologic? [cited 2013 Mar 4]. Available from: http:// answers.hhs.gov/questions/3262

2. U.S. Food and Drug Administration (FDA) [homepage on the Internet]. Center for Biologics Evaluation and Research. What is a biological product? 2013 [cited 2013 Mar 4]. Available from: http:// www.fda.gov/AboutFDA/Transparency/Basics/ ucm194516.htm

3. World Preview 2016. [cited 2013 Mar 4]. Available from: http://www.azcentral.com/news/election/ azelections/azfactcheck/fact-story.php?id=199.

4. GaBI Online - Generics and Biosimilars Initiative. FDA definitions of generics and biosimilars [www.gabionline.net]. Mol, Belgium: Pro Pharma Communications International; [cited 2013 Mar 4]. 
Available from: www.gabionline.net/Biosimilars/General/FDA-definitions-of-generics-andbiosimilars

5. Chow SC, Ju C. Assessing biosimilarity and interchangeability of biosimilar products under the Biologics Price Competition and Innovation Act. Generics and Biosimilars Initiative Journal (GaBI Journal). 2013;2(1). Epub ahead of print. doi: 10.5639/gabij.2013.0201.004

6. Declerck PJ. Biologicals and biosimilars: a review of the science and its implications. Generics and Biosimilars Initiative Journal (GaBI Journal). 2012;1(1):13-6. doi:10.5639/gabij. 2012. 0101.005

7. Peter P. A problem diagnosed. Center for Medicine in the Public Interest. [cited 2013 Mar 4]. Available from: http://www.cmpi.org/in-the-news/ in-the-news/a-problem-diagnosed/

8. Eisenberg C, Kupchyk A. Nixon Peabody [homepage on the Internet]. FDA issues biosimilar draft guidance. FDA Alert. 2012 Feb 28 [cited 2013 Mar 4].
Available from: http://www.nixonpeabody.com/ FDA_issues_biosimilar

9. U.S. Food and Drug Administration [homepage on the Internet]. Biosimilars. [cited 2013 Mar 4]. Available from: http://www.fda.gov/ Drugs/DevelopmentApprovalProcess/HowDrugsareDevelopedandApproved/ApprovalApplications/TherapeuticBiologicApplications/ Biosimilars/default.htm

10. World Health Organization [homepage on the Internet]. Pharmacovigilance. [cited 2013 Mar 4]. Available from: http://www.who.int/medicines/ areas/quality_safety/safety_efficacy/pharmvigi/en

11. Eli Lilly \& Co. Lilly's CEO calls for reform of nation's drug safety system. [homepage on the Internet]. 2007 Oct 2 [cited 2013 Mar 4]. Available from: http://newsroom.lilly.com/ReleaseDetail.cfm? ReleaseID=266917.

12. European Medicines Agency [homepage on the Internet]. Questions and answers on biosimilar medicines (similar biological medicinal products). 2012 Sep 27 [cited 2013 Mar 4]. Available from: http://www.ema.europa.eu/docs/en GB/document_library/Medicine_QA/2009/12/ WC500020062.pdf

13. Declerck PJ, Simoens S. A European perspective on the market accessibility of biosimilars. Biosimilars. 2012;2:33-40.

14. Class JN, Langis L. A patient-centered paradigm for the biosimilars market. Generics and Biosimilars Initiative Journal (GaBI Journal). 2012;1(1):17-21. doi:10.5639/gabij.2012.0101 006

15. GaBI Online - Generics and Biosimilars Initiative. FDA's public hearing on biosimilars draft guidances [www.gabionline.net]. Mol, Belgium: Pro Pharma Communications International; [cited 2013 Mar 4]. Available from: www.gabionline.net/Biosimilars/General/FDA-s-publichearing-on-biosimilars-draft-guidances/

DOI:10.5639/gabij.2013.0201.014

Copyright (c) 2013 Pro Pharma Communications International 